\title{
The Transformation of Media Reporters in the Perspective of New Media: from Traditional to Versatile
}

\author{
Jinhui Wu, Jinyong Lee(Kingsyhons Lee) ${ }^{\mathrm{a}} *$ \\ School of Journalism and Communication of Jinan University, Guangzhou, Guangdong, China \\ a409832327@qq.com \\ *Corresponding author
}

\begin{abstract}
With the rapid development of information technology and network technology, the quantities and the types of new media have expanded all the time. In addition, the boundary of these media is getting more and more ambiguous, the speed of their integration gets faster and faster and the traditional media has participated more and more in the work of edit and operation. And that requires the traditional reporters to be more versatile and improve both their thinking mode and technologic capacity in order to go with the flow.
\end{abstract}

Keyword-New media; Traditional media reporters; Transformation from traditional to be versatile

\section{INTRODUCTION}

As the society has entered a transition period, the reform is expanding continuously with greater range and deeper extent. When reform has penetrated into the cultural industry, the media also have, actively or passively, to keep up with the pace of reform. Once in the period of reform and opening up, the journalists have made a big fanfare for the reform of state-owned enterprises and their employees' identity. And now the journalists themselves are faced with the fate of the mutation, and are pushed from the shore to the cusp. The journalists who have long been surrounded by the voice of "crying wolf" finally are going to dance with the "wolf" [1]

In 2009, the Southern Metropolis Daily put forward the idea to build a "Southern Metropolis Omnimedia Cluster", changing from a single media to multimedia, in order to establish the media's production capacity, to increase the operating capacity and the ability to communicate, and ultimately to realize the transition to Omnimedia Group [2]. As equal leader among the metropolitan newspapers, Huaxi Metropolis Daily, on November 2, 2011, launched the "Magic Code of Huaxi Metropolis Daily". Readers can install QR code software in their smart phones to identify the "magic code" on the newspaper, so that they can automatically link to the videos related to the news or get the real-time traffic information. It realizes the assemblage of newspaper, audio, video and network, allowing readers to enjoy the convenience brought by technological innovation.

We thought that the media market was not really mature. Under the special market conditions and the regulatory environment in China, there is reason and space for the paper media to live on. As long as the society is still progressing towards civilization and democracy, newspapers will survive. But technology has changed that all. The truth is that Chinese newspapers are already facing a crisis of survival while they still are not mature. When the entire news industry is inevitably caught in an "Omnimedia Whirlwind", little is known about what omnimedia is and what is omnimedia for. The unsettled media environment makes all the journalists feel the urgency of the transition. During this response process, the traditional journalists with different mental state, different attitude to life have different trade-offs standard, so this group is divided. Some give up the identity of journalists and have another life such as early retirement, laid-off workers or re-employment. And some others have the courage for self-transformation to adapt to new situations, transformed into a pioneer in the new media.

\section{THE NECESSITY OF TRANSFORMATION UNDER THE IMPACT OF NEW MEDIA}

There are many reasons for the transformation of traditional media. For example, the media living environment, the identity of journalists and so on have a certain impact on the journalists' choice of the transformation. But the most important reason is the new media's impact on traditional media. This impact began in 2005, when Xinhua ranks the term "Web2.0" No. 2 in the Ten New Media Hotspots. [3] The core changes brought about by this technology is interactivity. Readers are users, that is to say, they are content viewer and also are involved in creating the site. This participation is achieved through the creation and dissemination of content. Thus, the reporters and editors need to be redefined. They will still play the role as a message disseminator, a manuscript supervisor or a content monitor. But it will be more and more difficult, because their powers to determine the headlines have been deprived. The most typical is the social media, which has already eliminated the traditional reporters and editors from its rules and mechanisms. According to DCCI, a historic leap has appeared in the Chinese Internet: the flow of content generated by users outnumbers that produced by the website. [4] The superiority of reporters coming from the right to speak vanishes in quantitative terms. That an essay with one thousand characters is no better than a micro blog is a usual fact.

However, in the face of the WEB 2.0 wave, traditional 
journalists do not have claims of crisis as that of WEB1.0; because they know what the new media will eliminate is not news producers but newsprint. American Professor from North Carolina State University, Philip Meyer gives the death schedule of the newspaper in his article The Vanishing Newspaper: Saving Journalism in the Information Age: "the last daily newspaper reporter will check out in 2044, October 2044, to be precise."[5] But with the rapid development of digital information technology and new media, the boundary of the original media and industry breaks down constantly. Whether it is passively or actively, it has become an inevitable choice for the newspaper industry to adapt and integrate into the era of Omnimedia. The current demand of the media employment has to focus on the development of media convergence. Thus versatile talent with vision of cross-media has become a trend. It can be expected that in 2044 there will still be reporters, but his article will be published on the screen.

\section{THE WAY OF TRANSFORMATION IN THE CONTEXT OF NEW MEDIA}

The digital revolution has brought profound changes to the news media. It has created a new media form-network. At the same time, the platform has also become an important new source for news reporters looking for news and information. However, if we only take the network as the fourth medium, we would have a risk of overlooking the convergent journalism such an important innovation process. The digitization of information has changed other media, like newspapers, radio and video have been forced to change to adapt to this trend. Reporters who work in old analog media for the first time see no barrier to separate them, and thus they also realize that cooperation is possible. The usual media integration pattern (Dupagne and Garrison, 2006) has the following elements. From a technical point of view, it involves the digitization of information; from a business perspective, it emphasizes cooperation and consolidation between media groups and the feasibility of content re-use in different ways, and it forces the government to think over regulation forms of a new media policy. In addition, the convergence process has a very important impact on journalistic work habits and the role of the reporters [6]. Issuers and Editorial Manager would have to use this new approach to gain profit, and the reporters must learn how to work inside the new media environment.

A. Hardware requirements: armed with skill to achieve transformation

In omnimedia era, the basic competency requirements of reporters are the same. It still requires keen news sense, good interview skills, strong writing skills and a unique entry point for planning. In addition, the reporter should be able to cope with challenges in the environment of omnimedia, including skillfully use a variety of camera equipment as well as office editing and non-linear editing software, and knowing how to do live report, interviews and emcee. From the perspective of hardware requirements, it has been insufficient for the reporters of the new media age to meet the job requirements if they are only equipped with the four traditional abilities.

From the job posting, it is not difficult to find out change in the requirement for the reporters. The most obvious one is that except for the text reporters, multimedia journalists are in greater need. They have to play many roles. First of all, they have to be a journalist and tackle the work like writing a piece of information, news report, review, speech etc. Secondly, they must also have the competency to show up on camera like an on-location host and provide a complete picture of the news events. Last but not least, they also have to know how to use the camera and video camera, as well as office software and non-linear editing. Front-line reporters need to be a kind of new capable reporter armed with a variety of digital devices. They would rapidly and timely release all news events in the mobile newspaper or on the websites, and then write the reports for the next day newspapers according to the hotspots. This pattern helps to form the complementarities and integration between newspapers and network. And it achieves the combination of the timeliness, the scale and the depth of the reports through a variety of media channels in different forms.

Taking Liu Ke, who is a photographer of Southern Metropolis Daily for example, we can see that it requires more equipment to be a photographer in the age of omnimedia. In the multimedia age, as a photojournalist, his day-to-day news gathering equipment includes a 5D Mark II and a 5D Mark III, two lens, one flash at least, portable continuous light source, a monopod or tripod, a viewfinder, a highly directional microphone and a professional recorder [2], which are very hard to bring to the scene. In general news gathering, photographers still center on the picture. But if possible, they would shoot video, which would be edited and integrated by the AV Production Department to be the materials required by omnimedia.

All in all, this is the omnibearing considerations of planning ability, new gathering skills, interview skills, technical capacity, and even the on camera ability. Thus, with only pen and mouth in the new development stage of the paper media, it is not enough for the reporters. They have to possess the ability of planning, interviewing and writing, while taking into account the ability of paper editing and video editing.

\section{B. Software requirements: transform based on the thinking of multimedia}

Above is the hardware requirements, opposite to which is the software requirements, and that is to understand the different appeal points as well as the different expressive styles between the two media systems. Reporters should not only feed the paper media, but also feed the corresponding network media. From the viewpoint of measuring the ability, it's like an upgrade test of their soft power. It requires reporters to feed both the paper media and network media at the same time, to master the respective advantages and appeal points, as 
well as the expression styles.

Omnimedia Editing System platform is a back-office support system supporting various modes of transmission such as text, graphics, audio, video, text messages and so on. Media groups usually have two lines to transmit information to its subordinate media--public reports and special feed. Public reports are for all media, and on the contrary special feed is only for one specific media. And thus it generates a distinction between the report content within the media group. Omnimedia Editing System uses real-time rolling release of the news, and posts a message, according to the respective propagation law of the media, in turn to the website - mobile news - e-reader information network - paper media - internal reference publishing house. As a result, it transforms from getting news first to release news first. [7]

The competency requirements of reporters for the above technology platform can be summarized as a change from simple to versatile. According to the different position and demands of the media, the group would plan and gather various types of integrated information suitable for mobile news, website, video, or the newspaper. At the scene of the news events, the reporters can release news flash with their mobile phones, photograph with the camera or record with a video camera, through which they can have an all-round, multi-level, multi-dimensional segregation and integration for the event so as to form information products with different positioning, different personality and different characteristics. So the first requirement of the reporter's work is to collect material. The material includes three forms: images, videos and audio. Unlike only focusing on the moment in the traditional media, we must have a broader view to think of more forms of material, such as continuous dynamic combination of the screen, such as those people who get involved in the stories, and such as the environment which helps to explain the topics.

Paper media is developing towards omnimedia. Low-cost, fast-pace and high efficiency are the key factors for its survival. News gatherers and editors are equipped with both hardware and software, and develop from simple reporters to versatile journalists. This is the inevitable requirement of media development. Compared to new media, paper media has an advantage to be a frozen art, with also an obvious disadvantage, that is it can only rely on the reporter's pen to represent the scene, thus the expression form is monotonous and lack of dynamic. The internet as a borderless media has a powerful feature that it can break through the objective restrictions of time and space. It can keep running around the clock and anyone can use this platform to obtain information. That the paperwork reporters transform to become omnimedia reporters possesses the advantage to break through the limitations of the newspaper, changing from posting message only once for a day to posting at any time, which also allows the reporters to have a random interaction with readers at any time. As far as effectiveness is concerned, an individual journalist cannot only handle written reports, but also photography reports and video coverage. That is to say, one person completes three tasks to secure the maximum efficiency of news gathering. In addition, the third advantage is that the video helps the print media to enrich its onefold communication way with only words and pictures, and to restore the scene in reality intuitively and objectively. Seeing convergent journalism from the perspective of reporters, it integrates the depth of the newspaper reports, the promptness of television reports and the interactivity of the network all into one.

\section{CONCLUSION}

With that technology ensures the possibility of this process and continues to explore new boundaries, the general trend of media content and its value is evolving to be all-inclusive, all-sharing and distributed. But traditional media reporters still may be the most valuable node in the information flow. New media environment does not necessarily mean that some of the most basic criteria of the traditional media are completely buried, but means to seek the integration of society, mobility and intelligence. Facing the new situation and new demands under the new era, traditional media reporters must reinstall systematically, from the ideology to practices, from basic theory to practical operation and from the idea to the means of expression, so as to ensure the career rebirth in the news industry. [1]

The new media environment has been so formed that the traditional media reporters either evolve or wait to be eliminated. Some reporters will be out in the process, but those who are not defeated will become stronger.

\section{REFERENCE}

[1]Ma, D.S. 2010. Traditional Journalists Should Reinstall for Rebirth (In Chinese). Young Journalist. 11.

[2]Wang, J.C. 2012. Versatile Reporters-We Are On the Way (In Chinese). News Front. 8.

[3]Liu, G. 2011. The Reason of the Transformation of Journalists (In Chinese). Chinese Journalist. 12.

[4]Data Center of China Internet. 2011. Blue Book of Mobile Internet (On Line). Available http://www.199it.com/archives/42962.html

[5]Philip Meyer. 2007. The Vanishing Newspaper (In Chinese). (Zhang W.P. Trans.). Beijing: Xinhua Publishing House.

[6]Dupagne, M. and Garrison, B. (2006). The Meaning and Influence of Convergence. A Qualitative Case

[7]Qu, Q. 2011. How do the Paper Media Journalists Transform to be Omnimedia Journalists. China Prefecture and Town Newspaperman. 